\title{
On the Valuation of Currency Options in Stressed Markets
}

\author{
${ }^{1}$ Abdulnasser Hatemi-J and ${ }^{2}$ Youssef El-Khatib \\ ${ }^{1}$ Department of Accounting and Finance, UAE University, United Arab Emirates \\ ${ }^{2}$ Department of Mathematical Sciences, UAE University, United Arab Emirates
}

\author{
Article history \\ Received: 11-05-2021 \\ Revised: 24-08-2021 \\ Accepted: 11-10-2021 \\ Corresponding Author: \\ Abdulnasser Hatemi-J \\ College of Business and \\ Economics, Department of \\ Accounting and Finance, UAE \\ University, United Arab \\ Emirates \\ Email: AHatemi@uaeu.ac.ae
}

\begin{abstract}
The current article handles the valuation of currency options in the market that is suffering from a financial crisis. The standard formulas for this purpose do not perform accurately. European foreign currency exchange options for both the call and the put versions are dealt with. It is assumed that the value of the underlying asset is a stochastic process that follows a modified Black Scholes model with an augmented stochastic volatility to account for the impact of the crisis. Under these settings, a closed form solution is offered for the option-pricing problem on foreign currency. The underlying solution is mathematically proved. In addition, some simulation results and an application are provided. The results based on the new formula accord better with reality compared to the standard formula.
\end{abstract}

Keywords: Currency Options, European Options, Financial Crisis, BlackScholes Model

\section{Introduction}

The evaluation of options is an integral part of modern financial risk management. Due to increasingly globalized financial markets currency options are increasingly used by multinational corporations and other institutions as well as individuals to neutralize the underlying exchange rate risk. It is widely agreed in the recent literature that the volatility of many exchange rates is increasing across time. This seems to be the case particularly during the last two decades. In the existing literature there is an option pricing formula for currency evaluation that is introduced by Biger and Hull (1983) as well as Garman and Kohlhagen (1983), which is based on the seminal work of Black and Scholes (2019). The well-known Black and Scholes (2019) option pricing formula is routinely used for the valuation of different options. It is a well-established fact in the literature that the volatility of financial assets tends to increase during a financial crisis period. Due to the increasingly dominant globalization effect of the financial markets, the likelihood of spillover effects and the resulting contagion is higher than ever. Therefore, the Black and Scholes (2019) formula might not perform accurately during a financial crisis.

The goal of the current article is to extend the existing formula for tackling the valuation of currency options in markets that are suffering from a potential financial crisis. It is during a financial crisis that the risk increases and the need for accurate hedging via derivative instruments

${ }^{1}$ For currency option pricing with stochastic interest rate see Amin and Jarrow (1991). See also El-Khatib and Hatemi-J $(2011,2012)$ and ElKhatib, Hajji, Al-Refai (2013) for price sensitivities calculation during crisis as well as for processes with jumps. including options is urgent. The standard option pricing formulas for currency options work well during normal circumstances but not during crises. The current article provides a closed form formula for currency option pricing during a financial crisis that is more accurate compared to alternative formulas. The focus is on a European option where the underlying asset is a foreign currency. The value of the underlying asset is assumed to be a stochastic process that follows a modified BlackScholes model with an augmented stochastic volatility. Under these settings, formulas for the option-pricing problem on foreign currency for both European call and put options are obtained in this study. Thus, our suggested approach might be useful under these circumstances.

\section{The Model}

Following Black and Scholes (2019) the subsequent assumptions to derive the currency option pricing formula are made:

1. The short-term risk-free rates for both domestic and the foreign markets, i.e., $r_{d}$ and $r_{f}$, are assumed to be known and constant ${ }^{1}$

2. It is assumed that the underlying distribution of currency prices within any finite interval is lognormal

3. No dividend payouts take place during the lifetime of the underlying option. ${ }^{2}$

${ }^{2}$ This assumption can be relaxed if the underlying market price of the asset is discounted continuously with regard to the dividends. 
4. There are no transaction costs.

5. Short selling is possible.

Nevertheless, unlike the original Black and Scholes approach the variance of the original asset does not need to be constant and it can increase across time. The following denotations are used in the current article. Let the probability space be defined by $(\Omega, F, P)$. Also let that $\left(W_{t}\right)_{t \in[0, T]}$ represent a Brownian motion process with $\left(F_{t}\right)_{t \in[0, T]}$ being the natural filtration generated by $\left(W_{t}\right)_{t \in[0}$ $T]$. In addition, let $P$ signify the risk-neutral probability. In this case the data generating process for the foreign currency at time $t$ that is determined via $P$, defined as $S_{t}$, is the following stochastic differential equation:

$$
d S_{t}=(r d-r f) S t d t+\left(\sigma S t+\beta e^{\left(r_{d}-r_{f}\right) t}\right) d W t,
$$

where, $t \in[0, T] S_{0}>0$ and $\beta$ is a constant. The denotation $\sigma$ signifies the volatility of the original asset. Note that $r_{d}$ is the domestic interest rate and $r_{f}$ is the foreign interest rate. Equation (2.1) accounts of the post-crash (crisis) effect via the parameter $\beta>0$. The below proposition provides the solution for the foreign currency SDE (2.1).

\section{Proposition 1}

For $0 \leq t \leq T$, the Eq. (2.1) has the following solution:

$$
S_{t}=\left(S_{0}+\frac{\beta}{\sigma}\right) \exp \left[\left(r_{d}-r_{f}-\frac{\sigma^{2}}{2}\right) t+\sigma W_{t}\right]-\frac{\beta}{\sigma} \exp \left[\left(r_{d}-r_{f}\right) t\right]
$$

\section{Proof}

The proof is inspired by the proposition one in the article of (El-Khatib and Hatemi-J, 2017). If for for $0 \leq t \leq T$ :

$$
\xi_{t}=\exp \left[\left(r_{d}-r_{f}-\frac{\sigma^{2}}{2}\right) t+\sigma W_{t}\right]
$$

then use Ito^ formula to get:

$$
d \xi_{t}=\left(r_{d}-r_{f}\right) \xi_{t} d t+\sigma \xi_{t} d W t, \xi_{0}=1
$$

And:

$$
d \xi_{t}^{-1}=\xi_{t}^{-1}\left[\left(-1\left(r_{d}-r_{f}\right)+\sigma^{2}\right) d t-\sigma d W_{t}\right]
$$

If $\beta=0$, the solution is $S t=S 0 \xi$. The variation of constants method can be used to find a general solution in the form of $\mathrm{St}=\xi t \mathrm{Zt}$ with $\mathrm{SO}=\mathrm{Z0}$ for the general case where $\beta$ $\neq 0$. In this case, using equation (2.4), the formula:

$$
d Z_{t}=d\left(S_{t} \xi_{t}^{-1}\right)=\xi_{t}^{-1} d S_{t}+S_{t} d \xi_{t}^{-1}+d\left[S_{t}, \xi_{t}^{-1}\right] .
$$

and the integration by parts for stochastic calculus give:

$$
Z_{t}=S_{0}-\frac{\beta}{\sigma}\left[h(t) \xi_{t}^{-1}-h(0)+\int_{0}^{t} \xi_{t}^{-1}\left(\left(r_{d}-r_{f}\right) h(s)-h^{\prime}(s)\right) d s\right],
$$

where, $h(t)=e^{\left[\left(r_{d}-r_{f}\right) t\right]}$ the solution of $S$ is then given by (2.2).

\section{The Option Valuation Formula}

Consider a European call option on the foreign currency with dynamics following the stochastic deferential Eq. (2.1).

\section{Proposition 2}

Assume that the dynamic of the foreign currency process, $\mathrm{S}_{\mathrm{T}}$, is defined by (2.1), then the premium of a European call option with strike $\mathrm{K}$ is provided by the following:

$$
\begin{aligned}
& C\left(S_{T}, K\right)=\left(S_{o}+\frac{\beta}{\sigma}\right) e^{-r_{f} T} \Phi\left(d_{1}^{\beta}\right) \\
& -\left(K^{e-r_{d} T}+\frac{\beta}{\sigma} e^{-r_{f} T}\right) \Phi\left(d_{2}^{\beta}\right)
\end{aligned}
$$

Where:

$$
d_{1}^{\beta}=\frac{1}{\sigma \sqrt{T}}\left(\ln \left[\frac{S_{o}+\frac{\beta}{\sigma}}{K+\frac{\beta}{\sigma} e^{\left(r_{d}-r_{f}\right) T}}\right]+\left(\left(r_{d}-r_{f}\right) T+\frac{\sigma^{2}}{2}\right) T\right)
$$

And:

$$
\begin{aligned}
& d_{2}^{\beta}=\frac{1}{\sigma \sqrt{T}}\left(\ln \left[\frac{S_{o}+\frac{\beta}{\sigma}}{K+\frac{\beta}{\sigma} e\left(r_{d}-r_{f}\right) T}\right]+\left(\left(r_{d}-r_{f}\right) T-\frac{\sigma^{2}}{2}\right)\right) \\
& =d_{1}^{\beta}-\sigma \sqrt{T}
\end{aligned}
$$

where the cumulative probability density function for a standard normal variable is:

$$
\Phi(x)=\int_{-\infty}^{x} \frac{e \frac{-u^{2}}{2}}{\sqrt{2 \Pi}} d u .
$$

\section{Proof}

We have:

$$
\begin{aligned}
& C\left(S_{T}, K\right)=E\left[\left(S_{T}-K\right)^{+}\right] e^{-r_{d} T} \\
& =E\left[\left(S_{T}-K\right)+\right] e^{-\left(r_{d}-r_{f}\right) T} e^{-r_{f} T}
\end{aligned}
$$

Now, by using Proposition 4 of El-Khatib and Hatemi-J (2017), we have: 


$$
\begin{aligned}
& E\left[\left(S_{T}-K\right)+\right] e^{-\left(r_{d}-r_{f}\right) T}=\left(S_{o}+\frac{\beta}{\sigma}\right) \Phi\left(d_{1}^{\beta}\right) \\
& -\left(K e^{-\left(r_{d}-r_{f}\right) T}+\frac{\beta}{\sigma}\right) \Phi\left(d_{2}^{\beta}\right)
\end{aligned}
$$

where, $d_{1}^{\beta}$ and $d_{2}^{\beta}$ are given respectively by (3.2) and (3.3) then replace the previous expected value in (3.4) to obtain (3.1). The proof is completed.

The following proposition can be used to determine the premium of a European put option.

\section{Proposition 3}

Assume that the dynamic of the foreign currency process, $\mathrm{S}_{\mathrm{T}}$, is defined by (2.1), then the premium of a European put option with strike $\mathrm{K}$ is given by

$$
\begin{aligned}
& P\left(S_{T}, K\right)=\left(S_{o}+\frac{\beta}{\sigma}\right) e^{-r_{f} T} \Phi\left(d_{1}^{\beta}\right)-\left(K e^{-r_{d} T}+\frac{\beta}{\sigma} e^{-r_{f} T}\right) \\
& \Phi\left(d_{2}^{\beta}\right)+K e^{-r_{d} T}-S_{0} e^{-r_{f} T}
\end{aligned}
$$

where, $d_{1}^{\beta}$ and $d_{2}^{\beta}$ are given by equations (3.2) and (3.3).

\section{Proof}

The price of a European put currency option is expressed as:

$$
\begin{aligned}
& P\left(S_{T}, K\right)=E\left[\left(K-S_{T}\right)^{+}\right] e-r_{d} T \\
& =E\left[\left(K-S_{T}\right)^{+}\right] e^{-\left(r_{d}-r_{f}\right) T} e^{-r_{f} T} .
\end{aligned}
$$

Then a similar approach is utilized as in proposition 2 to obtain the formula (3.5).

\section{Graphical Presentation of the Predicted Trajectory}

To compare the performance of our suggested approach with the standard one we present the predicted trajectory for the foreign currency spot rate in Fig. (1) and (2). The parameters for these simulations are presented in Table 1 and 2 .

In both graphs the suggested approach better depicts the effect of increased volatility that characterizes the spot rate in real world compared to the standard approach. This effect is more prominent in Fig. 2 in which the parameter value of is higher.

These graphs illustrate that the suggested approach accords well with the reality since the exchange rates are more volatile than what the standard approach could capture.

\section{An Application}

In this section an application is provided to demonstrate how the suggested currency option formula performs compared to the standard one. The inputs are presented in Table 3. The estimated premiums for both call and put currency options via each formula are presented in Table 4. As it is evident from these results the alternative formula provides a lower premium for a currency call option and a higher premium for a currency put option compared to the respective premium obtained by the standard formula. These results make sense since during a potential crisis the currency price is expected to go down, which means the likelihood that the call option will be exercised decreases will the opposite is true for the put option in reality.

Notes: Here, we have $\sigma=$ the standard deviation, $\mathrm{rf}=$ the foreign risk-free rate, $\mathrm{rd}=$ the domestic risk-free rate, $\mathrm{S}=$ initial currency spot exchange rate, $\mathrm{T}=$ time to maturity as a fraction of year, $\mathrm{K}=$ exercise currency exchange rate and $\beta=$ the parameter capturing the effect of the crisis.

Table 1: Inputs for Fig. 1

\begin{tabular}{lll}
\hline Parameter values & Model standard & Modified model \\
\hline Spot rate $(S)$ & 7 & 7 \\
Volatility $(\sigma)$ & 0.05 & 0.05 \\
Interest & 0.02 & 0.02 \\
differential $\left(r_{d}-r_{f}\right)$ & & \\
Time step $\Delta t$ & 0.001 & 0.001 \\
$\beta$ & 0 & 0.5 \\
\hline
\end{tabular}

Table 2: Inputs for Fig. 2

\begin{tabular}{lll}
\hline parameters & $\begin{array}{l}\text { Values for } \\
\text { standard model }\end{array}$ & $\begin{array}{l}\text { Values for } \\
\text { modified model }\end{array}$ \\
\hline Spot rate $(S)$ & 7 & 7 \\
Volatility $(\sigma)$ & 0.05 & 0.05 \\
Interest & & \\
Differential $\left(r_{d}-r_{f}\right)$ & 0.02 & 0.02 \\
Time step $\Delta t$ & 0.001 & 0.001 \\
$\beta$ & 0 & 1 \\
\hline
\end{tabular}

Table 3: Information on an original risky financial asset

\begin{tabular}{ll}
\hline Parameters & Values \\
\hline$\sigma$ & 0.25 \\
$r_{f}$ & 0.01 \\
$r_{d}$ & 0.015 \\
$S$ & 2.2 \\
$T$ & 0.75 \\
$K$ & 2.3 \\
$\beta$ & 0.5 \\
\hline
\end{tabular}

Table 4: The estimation results of the premiums for call and put currency options

\begin{tabular}{lll}
\hline Estimated values & Standard model & Modified model \\
\hline $\begin{array}{l}\text { Premium for a Call } \\
\begin{array}{l}\text { Currency Option } \\
\text { Premium for a Put }\end{array}\end{array}$ & 0.15016 & 0.04940 \\
Currency Option & 0.24087 & 0.53712 \\
\hline
\end{tabular}




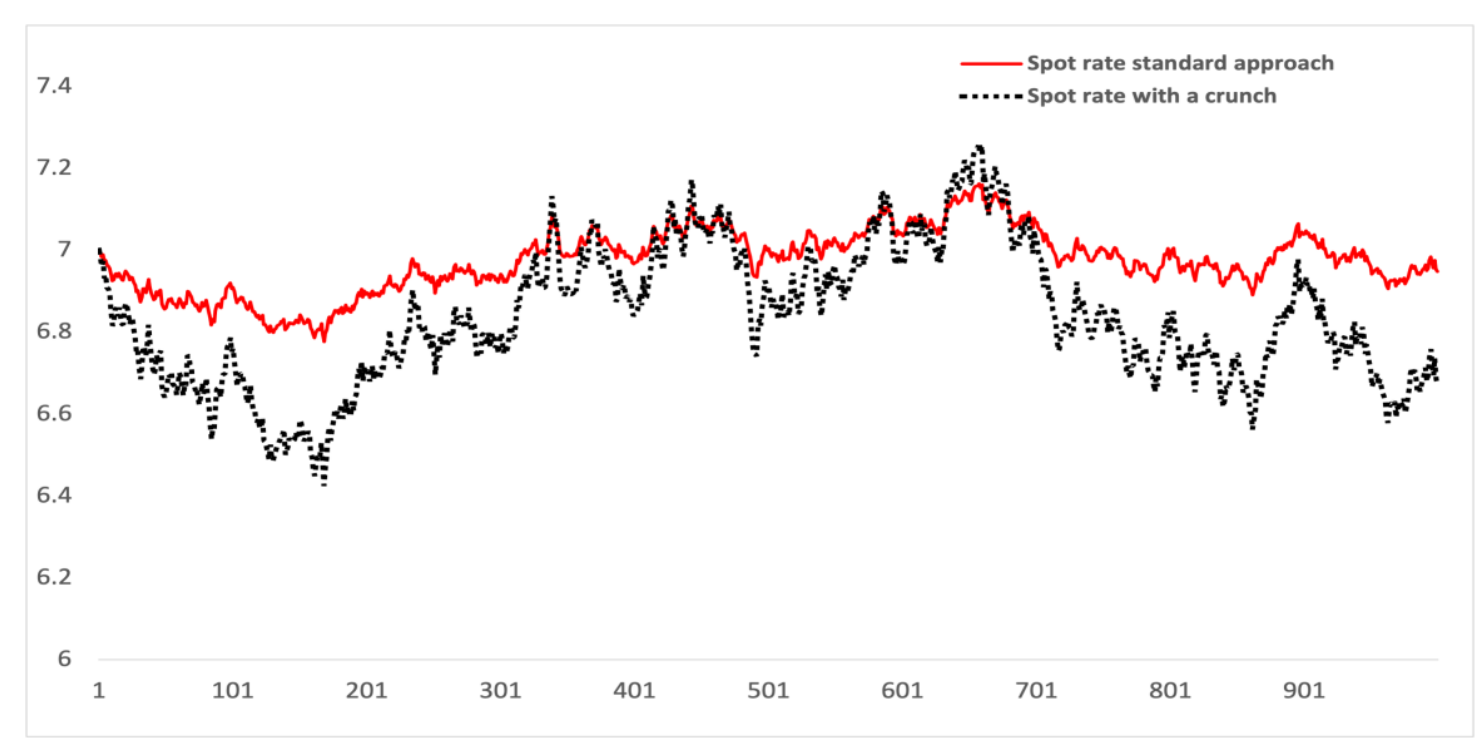

Fig. 1: The predicted trajectory for the foreign currency spot rate based on standard approach and our suggested approach. The horizontal axis represents time and vertical axis provides the values of the spot prices

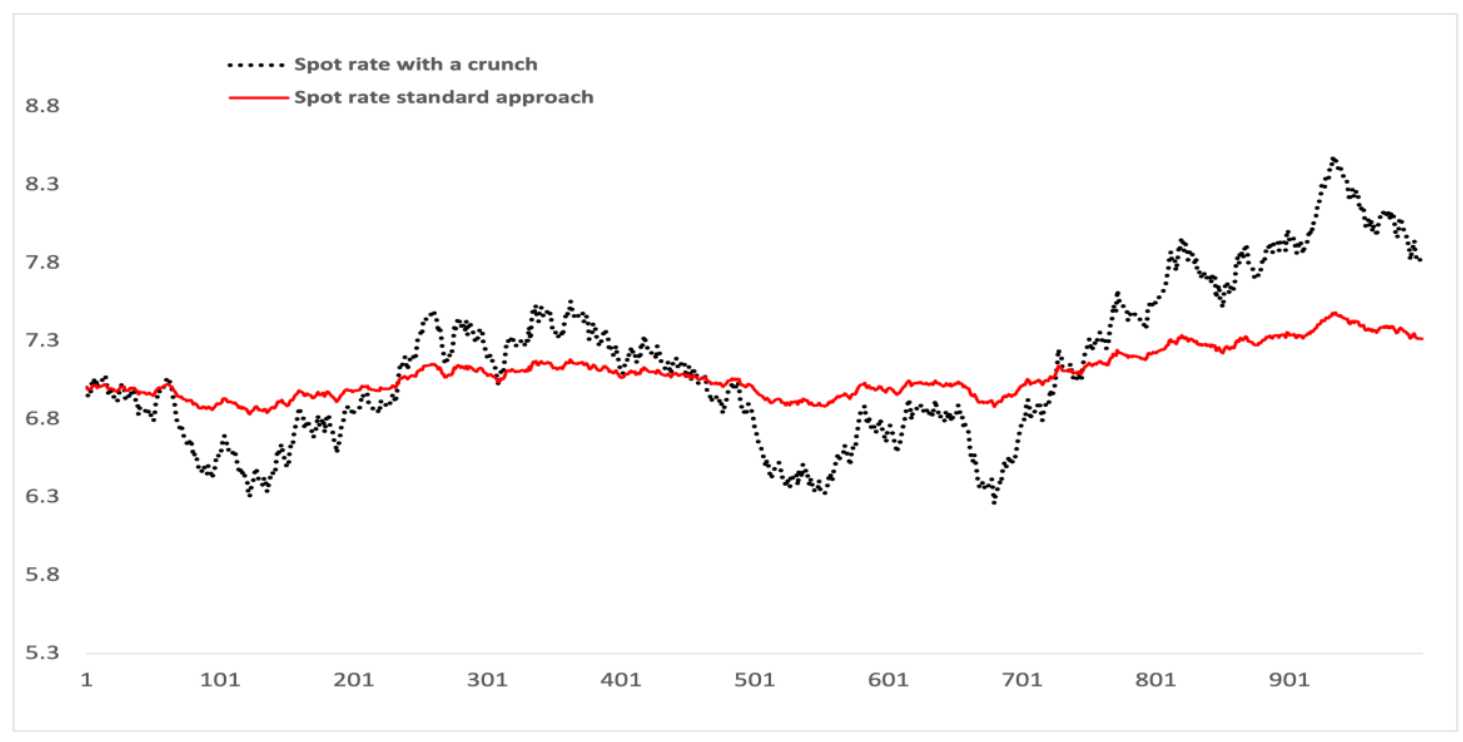

Fig. 2: The predicted trajectory for the foreign currency spot rate based on standard approach and our suggested approach. The horizontal axis represents time and vertical axis provides the values of the spot prices (Higher case)

\section{Conclusion}

This article deals with the issue of currency option pricing, which is gaining increasingly importance in globalized financial markets. A modified version of the standard model for the evaluation of both call and put currency options during a financial crisis is suggested. A closed form solution is provided and a mathematical proof for the underlying solution is given. Some simulation results are also generated, which demonstrate the predicted trajectory for the foreign currency spot rate based on our suggested approach accords better with reality compared to the trajectory generated by the standard approach. In addition, an application is provided, which shows that the modified approach results in a lower premium for a call currency option and a higher premium for a put currency option compared to the corresponding values based on the standard approach. This seems to accord well with the reality since in a market that is characterized by a crisis the value of a call option is expected to decrease while the value of a put option is expected to increase assuming the ceteris paribus condition. 


\section{Acknowledgment}

The second author would like to express his sincere appreciation to the United Arab Emirates University Research Office for the financial support UPAR Grant No.31S369.

\section{Author's Contributions}

Abdulnasser Hatemi-J: Conceptualization, data analysis, writing-original draft, conclusions.

Youssef El-Khatib: Conceptualization, writingmethodology and simulations.

\section{Ethics}

This article is original and contains unpublished material. The corresponding author confirms that all of the other authors have read and approved the manuscript and no ethical issues involved.

\section{References}

Black, F., \& Scholes, M. (2019). The pricing of options and corporate liabilities. In World Scientific Reference on Contingent Claims Analysis in Corporate Finance: Volume 1: Foundations of CCA and Equity Valuation (pp. 3-21).

doi.org/10.1086/260062
Amin, K. I., \& Jarrow, R. A. (1991). Pricing foreign currency options under stochastic interest rates. Journal of International money and finance, 10(3), 310-329. doi.org/10.1016/0261-5606(91)90013-A

Biger, N., \& Hull, J. (1983). The valuation of currency options. Financial Management, 24-28. doi.org/10.2307/3664834

El-Khatib, Y., \& Hatemi-J, A. (2011). Computations of Price Sensitivities after a Financial Market Crash. International Journal of Applied Mathematics, 41(4). doi.org/10.1007/978-1-4614-2317-1_20

El-Khatib, Y., \& Hatemi-J, A. (2012). On the calculation of price sensitivities with a jump-diffusion structure. Journal of Statistics Applications \& Probability, 2012. doi.org/10.12785/jsap/010303

El-Khatib, Y., \& Hatemi-J, A. (2017). Option valuation and hedging in markets with a crunch. Journal of Economic Studies. doi.org/10.1108/JES-04-2016-0083

El-Khatib, Y., Hajji, M. A., \& Al-Refai, M. (2013). Options pricing in jump diffusion markets during financial crisis. Applied Mathematics \& Information Sciences, 7(6), 2319. doi.org/10.12785/amis/070623

Garman, M. B., \& Kohlhagen, S. W. (1983). Foreign currency option values. Journal of international Money and Finance, 2(3), 231-237. doi.org/10.1016/S0261-5606(83)80001-1 